\title{
The Impact of Management Accounting and How It Can Be Implemented into the Organizational Culture
}

\author{
Ahmed Mohamed Ameen ${ }^{1}$, Moataz Fathi Ahmed ${ }^{2 *}$, Meral Ahmed Abd Hafez ${ }^{1}$ \\ 1 Suez Canal Company, Cortopa Tower, Up Cerdite Agre Cool Bank, 41516 Ismailia, EGYPT \\ ${ }^{2}$ Osmason Complex, EGYPT
}

\section{*Corresponding Author: moataz_fathi_ahmed@yahoo.com}

Citation: Ameen, A. M., Ahmed, M. F. and Abd Hafez, M. A. (2018). The Impact of Management Accounting and How It Can Be Implemented into the Organizational Culture. Dutch Journal of Finance and Management, 2(1), 02. https://doi.org/10.20897/djfm/91582

Published: June 14, 2018

\begin{abstract}
Management accounting is increasingly becoming a critical decision making process in organizations across the world. Value in any organization has to do with the ability to generate profits and solve societal issues within the environment which the organization exists. This publication not only encourages the utilization of this system but also promotes the consistent application through the recommended approaches as discussed. To ensure consistency once the process of management accounting is adopted, it has to be adopted as a culture within the organization. This form of accounting, just like financial accounting is a type of enterprise management financial management tool, however, in MA, operations are analyzed for strategic decision making but in FA operations and costs ae analyzed mainly for reporting convincing investors on the sustainability of the business.
\end{abstract}

Keywords: management, culture, organizational, management accounting, accounting business

\section{INTRODUCTION}

Management accounting is increasingly becoming a critical decision making process in organizations across the world. According to the Chartered Institute of Management Accountants (CIMA, 2017, par 1), management accounting "is the sourcing, analysis, communication and use of decision relevant financial and non-financial information to generate and preserve value for organizations". Value in any organization has to do with the ability to generate profits and solve societal issues within the environment which the organization exists. Ostensibly, if the process can allow the organization to generate profits or meet its objectives, it is correct to argue that management accounting influences the decisions made in an organization, the utilization of resources and the maximization of the existing resources (Macintosh and Quattrone, 2010). Based on this realization, Ward (2012) defines management accounting as the process of developing accounting information which is then utilized by an organization's management in the making of decisions and the control of organizational processes. This ability to influence better management especially among the managers makes it a critical tool in the $21^{\text {st }}$ century corporations because competition is ever increasing amidst the increased use of technologies and globalization.

In this regard, managers in companies that seek to remain competitive have to also consider the possibility of implementing management accounting as part of the organization culture. This is because, once a system has been incorporated into the organizational culture, it becomes a continuous belief or principle that influences every aspect of the organization leading to continuous value or benefit from the process (Alvesson, 2012). In this regard, by implementing management accounting into the organizational culture, the benefits of this process can be long- 
term and sustain the competitive nature of the organization. Nonetheless, it is critical to recognize the fact that management accounting has always been confused or in some cases used interchangeably with the tem financial accounting. Tiapaleenmaki and Ikaheimo (2013) clearly state that financial accounting is different from management accounting and cannot be used interchangeably. Instead, as forms of accounting, they can be used together within an organization leading to maximization of both process. This publication will therefore discuss the differences in these two accounting processes but major on the impacts of management accounting and how its implementation can be affected into the organizational culture. The publication will also analyze the theories related to the implementation of management accounting and compare its utilization across different types of organizations. The roles of management accountants will also be mentioned towards explaining how managers can effectively ensure the process is integrated into the organizational culture.

\section{APPLICATION AND SCOPE OF MANAGEMENT ACCOUNTING}

Sean Stein (2017) define management accounting as the process by which skilled accountants provide both financial and non-financial information to managers across different departments within an organization to guide their decisions on specific issues within the organization. In this regard, management accountants are like partners to the decision making process as their expert knowledge determines the strategies, decisions and the plans to be made by the management in an organization (Sean Stein, 2017). Managers have to consistently consult management accountants in case they exist in their organizations before they make critical decisions. The ICMA (2017) noted and explained that the roles of management accountants extend to three specific areas of organizational management: strategic, performance and risk management. In strategic management, ICMA (2017) notes that the management accountants partner with the management in the development of strategic goals, systems and their implementation. In such cases, Sean Stein (2017) notes that the management accountants will discuss issues like how the strategy can yield more profits, how the strategies can reduce cost and how the strategies would sustain the financial health of the organization.

In performance management, management accountants make decisions that ensure the operations of the organization are profitable, sustainable and within the set standards (Macintosh and Quattrone, 2010). This role would therefore require that the management accountants should always audit and gauge the effectiveness of each step vis-à-vis the desired goals of the company. Finally, the management accountants have an obligation to manage risks in organizations so that every operation within the organization would contribute to the attainment of their objectives (ICMA, 2017). In risk management, Sean Stein (2017) states that management accountants have to set parameters for not only detecting risks but to also manage after the risks after informing the management of its existence. To this point, it is clear that the management accountant not only works with the highest level of management in the organization but also other mid-level managers within the organization. Their operations are also not limited to specific departments but the entire units or departments within the organization. These include: marketing, sales, human resources and finance. Their roles in these departments include, setting of prices, determination of compensation, valuation of company resources and targeted investments, auditing of performances, and determining IT systems within an organization (Macintosh and Quattrone, 2010, Sean Stein, 2017). These roles of the management accountant therefore make him or her answerable to the management within the organization, and not any other external entity or stakeholder within the organization (Sean Stein, 2017). However, it is for this reason that an organization may choose to employ a management accountant or not-but in most cases organizations choose to employ a management account.

\section{DIFFERENCES BETWEEN MANAGEMENT ACCOUNTING AND FINANCIAL ACCOUNTING}

Management accounting and financial accounting are conflicting to some people yet as it will be illustrated, these concepts are completely different. To understand the differences, it is important to understand the application and scope of each of the concepts. Whereas the scope of management accounting has been aforementioned, this section will begin by describing financial accounting. Through the discussion, the emerging differences between financial accounting and management accounting will be emphasized. According to Elliot and Elliot (2017) financial accounting or reporting refers to the process in which an appointed accountant tracks and reports on all financial transactions transacted by the company. This process is guided by local and international standards of report development and reporting. Prior to mentioning the regulators, it is important to recognize the fact that the summaries made, analyses developed and the report created is meant for external use and this refers to the stakeholders or owners of the organization (ICMA, 2017). Unlike the management accounting information, financial accounting information is meant for the public as a reflection of the organization's financial performance 


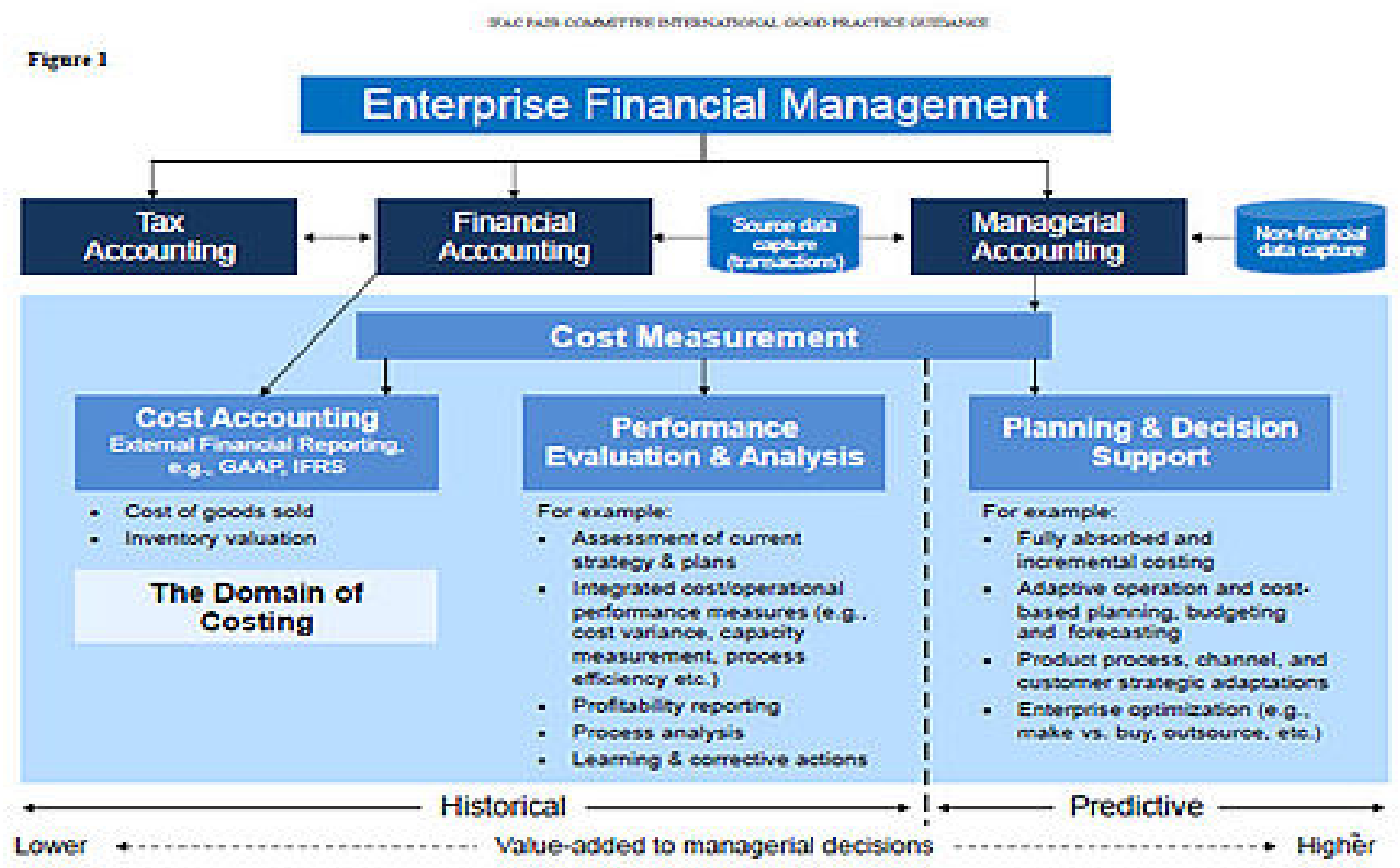

Figure 1. Classification of the Enterprise Financial Management Processes. Sourced from IFAC (2011)

and state. With this information, stakeholders can decide whether to continue transacting with the organization or invest (Elliot and Elliot, 2017). This is common especially for companies that are publicly traded in the stock market.

Financial statements issued by the financial accountants are expected to be provided as a routine (quarterly or annually); without which, an organization can be blamed for breaking industry based regulations (ICMA, 2017). Some of the international regulations that ensure that organizations release financial accounting information are: The Generally Accepted Accounting Principles (GAAP) and the International Financial Reporting Standards (IFRS). These standardization principles are not typically regulators as aforementioned, but set regulations that have been internationally accepted and are used to compel organizations to continue releasing their financial statements and related information to the public (Elliot and Elliot, 2017). These frameworks also guide the institutions on how they should report on specific factors within the statements. This is different from the reports and analyses provided by the management accountants as they are not limited on their reporting by any international based standards or regulatory body. In fact, although they are skilled on how to report on the issues within their jurisdiction, they are often influenced on their reporting by the organizational requirements and operations. Financial accounting information is highly public and thus accessible to the competitors and customers whereas management accounting is strictly internal and this protects it from any competitors or external stakeholders (ICAM, 2017). In terms of the nature of information provided, financial accounting provides data on cash flows, incomes and losses, and financial position of the organization after balancing the statements (ICAM, 2017, Elliot and Elliot, 2017). In contrast, management accounting focusses on strategic information, overall performance and risk management information.

Other differences between financial accounting and management accounting include: First, financial accounting information is historical in nature as the report features transactions that were done for a specific period until the reporting date whereas the management accounting information is predictive and future-oriented (Ward, 2012, Elliot and Elliot, 2017). While providing information, management accountants will always focus on the impact of specific plans, operations and spending to the future existences of the business and objectives of the organization. Second, financial accounting can be case-based or limited to a specific organization and its operations and challenges, whereas management accounting is modelled depending on the preferred decision making approach of the organization (Aneliya, 2017). This aspect is related to the focus or scope where financial accounting focuses on the organization as a whole while management accounting can focus on specific issues and aspects of the organization like the tasks, departments or services. Due to the frameworks used in the standardization of financial reporting or accounting, these reports have a common reporting approach that would be notable in different organization (Elliot and Elliot, 2017). However, the management accounting process is unique based on what the managers in each organization requires or the management system or theory applied in the organizations (Ward, 2012). 
In general, both financial accounting and management accounting are critical to an enterprise's existence. In fact, the International Federation of Accountants (IFAC, 2011) classifies the two processes as critical enterprise financial management processes along with tax accounting. The table below by IFAC illustrates the three broad areas of financial management and the nature of information collected in the implementation of each accounting technique:

Based on Figure 1, managerial accounting is a cost measurement process in which cost accounting, performance evaluation and planning and decision support are included. In contrast, financial accounting is a cost accounting process. Financial accounting emphasizes the inventory and balance sheet and thus adds value mainly to the stakeholder while management accounting emphasizes the performances and guides decision making thus making it most valuable to the management.

\section{APPROACHES AND TECHNIQUES OF APPLYING MANAGEMENT ACCOUNTING}

Management accounting is a system of organizational management whose implementation, although flexible depending on the type of operations within the organization, is dependent on specific approaches and techniques that determine the scope of costing or operational analysis. Although every management accountant can use a specific method or technique that best suites its organization, the freedom that comes with the random selection of the approaches increases chances of inconsistency (Ward, 2012). According to Clinton and Van Der Merwe (2006), since the beginning of the new millennium, organizations have continued to consider the application of management accounting for decision making but, most of the organizations lack consistency in their application of the specific approaches of management accounting like: Active-Based Costing (ABC), Resources Consumption Accounting (RCA), Grenzplankostenrechnung (GPK), Lean Accounting, among others. In some cases, these management accounting approaches are normally referred to as management accounting methodologies. Each of the methodologies is applicable in organizations based on the different intentions of the management accounting process. Nonetheless, Clinton and Van der Merwe (2006) state that if they are applied comprehensively, they would have a larger impact to the decision making process as they would be able to offer a reflection of the financial state of operations, lead to optimization of the management roles and encourage better performance while rewarding continued success. This research will therefore promote the adoption of MA as and a comprehensive approach in the utilization of the methodologies.

Management accounting methodologies vary based on their scope, effect and applications. To begin with, the Active-based costing (ABC) method was explained by Kaplan and Bruns by stating that, with the continued application of technologies in the manufacturing industry, productivity also increases and this translates to a notable decline in direct costs like labor and the costs of raw materials (Liu et al., 2010). In contrast, this translates to a rise in indirect costs (Liu et al, 2010). The main intention of this type of costing is to eliminate the costly or overpriced processes while restructuring the organization to introduce or utilize processes that lead to better yields (Clinton and Van Der Merwe, 2006). Manufacturing industries would benefit from such a costing as it allows the management to have a view of both their processes and resources vis-à-vis their desired outcomes. It helps to ensure the output is as high as the input and can ensure continued survival and growth of the industry. The organization will however have to develop an approach to tackle the rising indirect costs; perhaps even evaluate the viability of the new approaches amidst the rising indirect costs. In German organizations, cost accounting is also done but mainly to ensure better control of the operations and processes, while increasing the level of modernity in processes (Ossimitz et al., 2016). This is the concept of Grenzplankostenrechnung or GPK which is often done for internal purposes to ensure that the project and plant managers have maximum control of the internal processes (Ossimitz et al., 2016). Other than focusing on profitability as is the case in output-input based processing like $\mathrm{ABC}$, this method allows for the integration of costing systems to enhance control for maximum functionality (Clinton and van der Merwe, 2006). The technique is common in German based industries and continues to be applied as it allows the incorporation of new technologies while still controlling the cost implications of the processes.

It is also important to acknowledge the fact that although GPK, just like the other methodologies is not aimed at ensuring accountability for external purposes, the ability to ensure control of internal processes leads to better organizational accountability that ensures the organization is operating within the requirements of accounting regulators like the IFRS and stock exchange authorities (Ossimitz et al., 2016). This therefore, implies that the method promotes the benefits of both financial accounting and management accounting. The RCA method is an advancement of the GPK and also ensues the maximization of the internal processes. However, as Fisher and Krumwiede (2012) note, RCA is based on principles and is more dynamic in its applications. These principles are those developed and used in GPK and are advanced in the RCA through a comprehensive approach. For instance, instead of simply applying elements like cost type accounting (separation of costs based on use), product cost accounting (costs of products), cost center accounting (accountability based on performance) or profitability 
management (for long-term decision making) separately, RCA, integrates two or more of these techniques to ensure that the decision making system has considered the multiple options that determine the profitability and sustainability of the organization (Clinton and Van der Mewe, 2006). This comprehensive approach makes the method easily adaptable and able to ensure a consistent spending and resource maximization behavior as the different organization dynamics can be considered as they occur. Generally, ABC, GPK and RCA are methods that can be applied across numerous industries due to their comprehensive and integrated nature. However, in case the industry or organization adopts the lean manufacturing approach, lean accounting based on the Toyota production system can be applied. This technique can allow the flexibility of manufacturing processes especially when specific products are required within a specific time and thus the MA can establish how such manufacturing and processing needs can be advanced within specific times in future (Ahakchi et al., 2012). This accounting was developed when it was noted that organizations and industries can no longer depend on mass production only since different customers demand specific types of products based on the market needs (Ahakchi et al., 2012). By ensuring the changing production needs are met through lean manufacturing, the accountant can then adopt lean accounting to guide further decision making within the industry.

\section{IMPACTS OF MANAGEMENT ACCOUNTING}

Legaspi (2014) conducted a study to establish the impacts of management accounting in Philippine Industries and made the following conclusions. First, today's managers cannot ignore the role of management accountants since competition is increasingly causing the demand for quality products and services. Second, Legaspi (2014, p. 356) established that for all industries engaged in the study, the managers prioritized the following factors: "customer's satisfaction, running and controlling of management operation, quality of product/service, and company profitability". To achieve these, the managers felt that they needed a strong form of management system and management accounting was considered as the main tool towards guiding them to the realization of the stated goals (Legaspi, 2014). Finally, through Lynn's study it was clear that management accounting was more valuable and relevant to manufacturing industries as they constantly have to monitor their production costs, manage their pricing, budget their capital for present maximization and future sustainability, and effective decision making (Lynn, 2014). These findings by Legaspi (2014) summarize the findings and conclusions made by other researchers like Ward (2012), Macintosh and Quattrone (2010), and Elliot and Elliot (2017). Ward (2012) supported Legaspi's arguments by stating that through management accounting, managers are able to understand their current operations better and prepare themselves for the future. It guides the organization's vision, strategic objectives and preparedness for future risks (ICAM, 2017).

In the past, managers depended on their own management skills and theories that guided management practices at the time like the scientific management which focused on economic efficiency through rewarding staff based on the work done (Shafritz et al., 2015). Others like the "Theory X and Y" demanded that the managers have to motivate their employees consistently since better performance can only be achieved if the staffs are highly motivated (Sahin, 2012). Although these theories set the standard for effectively working organization, they mostly majored on the relationship between the staff and the organization. With continued trade across the globe and the demand for diverse products and services, increase in research and development in technologies, it was realized that it was no longer effective to simply focus on the staffs as the organization has numerous resources that affect the performance of organizations. The scientific management approach attempted to consider the machines and their effects to the output by noting that upon improving technologies, the machines would lead to faster service delivery as long as the staffs are also caused to maximize their stations. However, this approach and others before this were founded on the theory of mass production where most of the organizations only operated to maximize the output. According to Sahin (2012), this had negative implications like overworking of staff, inability to meet the dynamic market needs and high levels of wastages. Nonetheless, as established through this publication, MA can help factor the costs of production and operations vis-à-vis the talents, resources and market needs. Other than limiting the management to the impact of staffs, management accounting also notes how the raw materials sourced and used within the organization affect the technology selected, how the technologies selected affect the staff performance, how the staff performance affects the final products, and how these products or services affect the customer. In this regard, it is a comprehensive approach to decision making and can guide the short term goals and influence the long term goals for the sake of the organization's future. Even as markets become dynamic, MA ensures the organization diversifies its products and services accordingly (Ward, 2012; Legaspi, 2014).

According to Friedl et al. (2009), American managers in the recent times have proved to be highly inclined to adopt the German based systems of costing-GPK-in the management of the American companies. Ossimitz et al. (2016) add that this can mainly be attributed to the detailed nature in which the GPK can allow the German managers to understand their variable and fixed costs. The research by Friedl et al. (2009) further established that the GPK allowed the manager to have adequate data to make managerial decisions and provide the organization 
with an efficient IT system that could support all its operation. This cost accounting method was preferred over the ABC as GPK offered additional tools like the SAP that provide critical operational and production data in segments to the plant and overall organizational managers. However, the research by Friedl et al. (2009), also established that despite the increasing preference for GPK in the USA, it was impossible to identify an organization that solely applied GPK, instead, organizations preferred to utilize both GPK and ABC. This supports Clinton and Van de Merwe (2006) who established that by applying only one method of MA, an organization would fail to maximize the role of an MA within its industry. Ostensibly, Friedl et al. (2009), encouraged that based on the organization's resources, it is critical to identify at least two or more methods and maximize them towards ensuring that the role of the MA is fully attained. After all, GPK is a long-term approach whereas ABC is more short-term (Friedl et al., 2009). In the American case, it was also established that since the $A B C$ was inadequate, whereas the GPK led to more detailed costing and analyses, both methods have to be utilized but with stronger inclinations to the GPK.

The main benefits of GPK in an organization include: the ability to segment the findings and allow detailed analysis for plant and overall managers due to its IT based systems. To the organization, this means better efficiency and control of costs, effective short term decision making, precise planning, clearer indirect costs, better management structures, employees are better motivated, better business processes and support for long-term decision making (Friedl et al., 2009). Based on each of these benefits, an efficient operation and control of costs would help to eliminate wastes and ensure the operations are within the organization's budget, better management structures would help to ensure that responsibilities are effectively achieved, motivation of staffs would lead to their improved performance, better business processes would ensure improved profitability and long-term decision making would enhance the attainment of set strategies. Organizations with such strong internal structures contribute to the overall external perceptions of the organizations. For instance, good cost accounting through MA would ensure that the FA records are properly developed, clear and detailed, customers would receive value through the products sold and the managers would be able to sustain the operations of the organizations for a long time to the benefit of the stakeholders. It is however important to remember that although MA is purely an internal processes of cost accounting for strategic decision making, it can support the external performance of the organization.

Clinton and Van der Merwe (2006) states that the inability to effectively compare the various MA methodologies and techniques has always been a critical disadvantage to its implementation and application. This causes organizations to spend much on the MA initiatives while remaining poorly supported in the decision making processes (Ward, 2012). According to Friedl et al. (2009), one of the key approaches of ensuring that the organization is able to benefit is integrating the methods and adopting new technologies that help to narrow down on the different cost centers that continue to be increased in the organizations. Cost centers in an organization applying management accounting refer to the number of factors that increase or reduce the costs of operations within organizations (Friedl et al., 2009). In this regard, Friedl et al. (2009) state that smaller organizations always feel that as their organizations expand, they are likely to witness an increase in their cost centers whereas the large organizations believe that their cost centers are likely to decrease with time. Regardless of whether cost centers increase or decrease within organizations, it is clear that whenever an organization implements MA, the integrated methods can ensure that the cost centers ae effectively analyzed and the wealth of information generated becomes the greatest resource of the organization; as it can effectively balance its resources against their goals.

Legaspi (2014) and Friedl et al. (2009), were able to illustrate the continued desire to apply management accounting within organizations in Philippine and the US respectively. Although the current levels of applications are satisfactory at best (Clinton and Van der Merwe, 2006; Friedl et al., 2009), there is hope based on the ability to integrate the methods, the ability to adopt flexible methods and the ability to incorporate new software like the SAP system used in the GPK by German companies. The SAP is a type of Enterprise Resource Planning (ERP) system in which the organization is able to plan its operations based on a MA method leading to the desired benefits of the MA. The roles of the ERP ae not only limited to management accounting but also tax planning and financial accounting as noted by the IFAC (2011). In this regard, once the organization adopts an ERP system to supports the MA processes, it increases the chances of fulfilling all other financial management requirements like taxation and financial accounting as both of these are enshrined in the implementation of the ERP systems. Although different vendors sell these systems based on different functionalities, the general operation allows the analysis of numerous cost factors including taxation and other forms of accounting and this contributes to effective enterprise financial management. In general, the application of MA enhances the overall financial management and this contributes to the aforementioned benefits to the organization like: better management, efficiency in utilization of resources and improved staff and customer satisfaction. 


\section{IMPLEMENTATION INTO ORGANIZATION CULTURE}

To this point, the role of MA in organizations can be referred to as both inevitable and substantial, yet, its utilization remains even more critical as it can either enhance organizational success or contribute to its failure. This publication not only encourages the utilization of this system but also promotes the consistent application through the recommended approaches as discussed. To ensure consistency once the process of management accounting is adopted, it has to be adopted as a culture within the organization. Alvesson (2012) stated that organizational culture refers to the values and beliefs upheld within an organization and can be used as their identity. Culture has to do with the simple aspects like the interaction between the staffs and their customers to the management aspects like integrity and accountability. Management accounting is critical and thus can be considered as one of the management aspects that shape the entire organization. Based on the listed benefits of management accounting, including the ability to ensure the management is conversant with all the operations within the organization and how they are affecting the capital and other costs within the organization, the role of the management accountant has to be made permanent within the organization to ensure the benefits of their existence are realized (Sean Stein, 2017). Although it is not mandatory, an organization that allows this staff member to be part of its team creates a culture of management accounting as the accountant would be expected to report consistently and guide the management to be compensated. At the initial stages, such a role may only seem beneficial to the organization's management only but as other departmental heads begin to be engaged, the processes of accounting and reporting becomes a routine-a culture- that sticks throughout the organization's lifetime. As aforementioned management accountants can advise the heads of different units and by analyzing all operations within the organization, they can be able to note how performance is being compromised or how it is enhanced. Though their solutions, managers can then be able to use the noted information to make working decisions.

To sustain the culture of management accounting, the management accountants have to attend planning and strategic meetings as an obligation to the company and this can be ensured through structuring the organizations policies to reflect this. Policies are able to ensure implementation of effective approaches to management (Sean Stein, 2017), and this is an example of a case that would benefit organizations and improve their cultures. Policies can either be set internally or externally through regulators. Just like it is compulsory for organizations to conduct financial accounting for their stakeholders, management accounting can be made compulsory through the policies set within the organization. Change in management will therefore not affect such an existing culture as it is guided by the internal policies. This policy should cover the existence of the MA position and the scope of their roles within the organization. Additionally, the organization can choose to encourage the utilization of an ERP system where all financial management factors would be considered, and this should include the MA tools (Murthy, 2008). ERP is widely applied especially in large enterprises and vendors continue to incorporate features that would allow maximization through numerous functional tools. Adopting such a system would encourage its continued utilization based on the fact that it has numerous capabilities and it is relatively costly when limitedly utilized. The utilization of technologies has also been considered as one of the main reasons of the success of GPK method of MA in Germany and therefore by adopting ERP with a GPK based SAP software, a culture of technological maximization is created and enhanced. In the process, the utilization of MA is adopted as a culture that can be supported by technologies within the organization.

Since the role of the management accountants can affect the operations of individual departments and units within an organization, department heads should also be obligated to consult these accountants prior to making decisions. Unlike plant managers who may be obliged through the use of the SAP system that can provide fragmented data based on the operations, department heads may feel reluctant in the adoption of the system especially if the organization emphasizes that the MA role is mainly aimed at supporting the senior management's strategic goals. Ward (2012) is however keen to note that since organizations can be different based on their operations and activities, they should engage their management accountants carefully, perhaps through a structured approach that identifies the critical operational aspects of each unit or department. There are numerous management accounting processes like Activity-Based Costing (ABC), Grenzplankosterechnung (GPK), lean accounting, resource consumption accounting (RCA), among others (Sean Stein, 2017). ABC, GPK and RCA are the most popular as they are applicable in numerous organizations. Without an effective structure on how the MA should utilize these methods in the organization, the information available to the department heads may also be inappropriate, poorly utilized or ineffective in them. One of the most guaranteed approaches of ensuring the MA information on cost accounting is highly effective is combining different MA methods in the analysis of processes and development of guiding data (Sean Stein, 2017). In this regard, the possibility of integrating all these processes has to continuously be used to ensure the culture of management accounting is also accurate and detailed. In the long-term the organizations' performance improves, leads to competitive advantage and also the management has a support system that is effective to its needs. 
One of the strongest technique applied when seeking to create a culture in an organization is rewarding the culture (Aljaz, 2012). This causes the habit or approach to performance is sustained or even improved further. The successful application of MA can be noted in various ways including: the maximization of organizational resources, continued control of costs amid the growing organizational profits and better staff and customer satisfaction. Although the role of Mas can be limited to a single individual or a team of Mas within the organization, rewarding the efforts of the individual, team or the entire management can increase the continued implementation of the system as a cultural concept. Organizations should be able to specifically identify specific units (departments) of the organizations that have been able to effectively utilize data from the MA and reward their success, or the success of the entire management. Since the overall impact of the MA functions lie with the ability to ensure customer satisfaction, the organization can also consider rewarding management and other teams that continue to guarantee custome satisfaction. In the process, there would be higher motivation to ensure that the approach to decision making is sustained.

\section{CONCLUSION}

Management accounting (MA) is a decision making approach used to increase an organization's value by allowing its managers to make decisions based on evaluation of costs and other performance issues. It is holistic in nature and mainly performed for internal use. This form of accounting, just like financial accounting is a type of enterprise management financial management tool, however, in MA, operations are analyzed for strategic decision making but in FA operations and costs ae analyzed mainly for reporting convincing investors on the sustainability of the business. FA is also compulsory for organizations whereas MA is optional and dependent on the organization's ability to effectively utilize the information generated through the process. The impacts of MA make it a critical tool in organization's survival in the short and long term and therefore, this publication supports its application in all organizations. Such impacts include: the ability to guide the decisions made through the information provided, the ability to ensure maximization of both human and physical organizational resources, the ability to ensue strong organizational operations through the utilization of technologies and the ability to ensue satisfaction through the products and services provided by the organization. These benefits can be summarized as; better profits, increased satisfaction and enhanced organizational performance. Its application as a tool for decision making would have to be incorporated into the organizational culture to ensure continued realization of its benefit. To make it a cultural practice in the organization, the publication recommends that the organization should encourage its use through a policy, utilize ERP systems and technologies that ensure its use, encourage decision making in all departments based on the MA report, and reward the benefits of its use consistently.

\section{REFERENCES}

Ahakchi, R., Ahakchi, R., Yangjh, B. S. and Alilou, M. (2012). Lean accounting, adaptation tool lean thinking and lean production. World Applied Sciences Journal, 17(8), 1040-1045.

Aljaž, S. (2012). The impact of a project organisational culture and team rewarding on project performance. Journal for East European Management Studies, (1), 40.

Alvesson, M. (2012). Understanding organizational culture. Sage.

Aneliya, G. (2017). Management accounting and its place in the accounting system. Ikonomika I Komput" rni Nauki, $3(2), 36-49$.

Chartered Institute of Management Accounting (CIMA) (2017). What is management accounting? Available from: http://www.cimaglobal.com/Starting-CIMA/Why-CIMA/what-is-management-accounting/

Clinton, D. and Van Der Merswe, A. (2006). Management Accounting Approaches, Techniques, and Management Processes. Accounting, Audit \& Corporate Finance Library. May/June 2006.

Elliott, B. and Elliott, J. (2017). Financial Accounting and Reporting 18th Edition. New York: Pearson.

Friedl, G., Hammer, C., Pedell, B. and Kupper, H. (2009). How do German companies run their cost accounting systems? Cost accounting systems in German companies provide a high level of detail for managers, focus on cost centers and cost center accounting, and separate costs into fixed and variable components for easy analysis of profits. Management Accounting Quarterly, (2).

Fisher, J. G. and Krumwiede, K. (2012). Product costing systems: Finding the right approach. Journal of Corporate Accounting \& Finance, 23(3), 43-51. https://doi.org/10.1002/jcaf.21752

International Federation of Accountants (IFAC). (2011). Enterprise Financial Management. International Good Practice Guidance: Evaluation and Improving Costing in Organizations July 2009. International Federation of Accountants. 
Liu, X., Zhai, K., Meng, Q. and Song, X. (2010). Active-based costing model for iron \& steel enterprises. Computer Integrated Manufacturing Systems -Beijing-, 16(5), 1041-1052.

Macintosh, N. B. and Quattrone, P. (2010). Management accounting and control systems: An organizational and sociological approach. John Wiley \& Sons.

Murthy, C. V. (2008). Enterprise Resource Planning and Management Information Systems: (text and Case Studies). Mumbai [India]: Himalaya Publishing House.

Ossimitz, M., Wieder, B. and Chapman, P. (2016, May). Management Accounting Functionality in SAP SolutionsImplications for Research and Practise. In International Conference on Enterprise Systems, Accounting and Logistics (ICESAL) 2016.

Sean Stein, S. (2017). Strategic Management Accounting: Delivering Value in a Changing Business Environment through Integrated Reporting. New York: Business Expert Press.

Şahin, F. (2012). The mediating effect of leader-member exchange on the relationship between Theory X and Y management styles and affective commitment: A multilevel analysis. Journal of Management \& Organization, 18(2), 159-174. https://doi.org/10.1017/S1833367200000936

Shafritz, J. M., Ott, J. S. and Jang, Y. S. (2015). Classics of organization theory. Cengage Learning.

Taipaleenmäki, J. and Ikäheimo, S. (2013). On the convergence of management accounting and financial accounting-the role of information technology in accounting change. International Journal of Accounting Information Systems, 14(4), 321-348. https://doi.org/10.1016/j.accinf.2013.09.003

Ward, K. (2012). Strategic management accounting. Routledge. 